\title{
Amplified interleukin-15 expression vectors for cancer immunogene therapy
}

\author{
XIANGHUI HE, WEIDONG LI, NING LU, FENG QI, NA ZHAO, YUJIE QIU and LIWEI ZHU \\ Department of Surgery, Tianjin General Surgery Institute, \\ Tianjin Medical University General Hospital, Tianjin 300052, P.R. China
}

Received December 27, 2007; Accepted February 14, 2008

\begin{abstract}
Interleukin-15 (IL-15) is a pleiotropic cytokine that plays a key role in the regulation of both innate and adaptive immune responses. It promotes the survival, proliferation, activation and maintenance of natural killer and $\mathrm{CD}^{+} \mathrm{T}$ cells. It also stimulates the function of neutrophils, macrophages and dendritic cells, and could therefore be a potential cytokine for cancer immune therapy. The therapeutic effects of cytokines are related to their expression levels. In this study, we investigated an amplified IL-15 expression plasmid vector, pHi2spIL15-CMV-tat, and a carcinoembryonic antigen (CEA)positive tumor-specific amplified IL-15 expression plasmid vector, pHi2-spIL15-CEA-tat. In pHi2-spIL15-CMV-tat, IL-15 expression was driven by HIV2 LTR, which was transactivated by CMV promoter-controlled expression of HIV tat. In addition, the native IL-15 signal peptide was replaced by the IL-2 signal peptide to enhance its secretion. A significant amount of IL-15 expression was achieved when transfected into tumor cells in vitro. In order to target IL-15 expression in CEA-positive cells, the CEA promoter positively-controlled IL-15 expression plasmid vector pHi2-spIL15-CEA-tat was constructed by replacing the CMV with the CEA promoter. Efficient and targeted IL-15 expression was achieved in CEApositive tumor cells by pHi2-spIL15-CEA-tat.
\end{abstract}

\section{Introduction}

Cancer is one of the leading causes of death in the world. In dissecting the molecular mechanism of carcinogenesis, gene therapy has been developed as a promising approach to cancer treatment. In fact, more than two-thirds of gene therapy clinical trials are designed to control cancer (1). Gene therapy with cytokine genes provides a strategy to enhance immune responses to cancer, simultaneously avoiding systemic adverse

Correspondence to: Dr Xianghui He, Department of Surgery, Tianjin General Surgery Institute, Tianjin Medical University General Hospital, No. 154 Anshan Road, Tianjin 300052, P.R. China

E-mail: humphreyhe@163.com

Key words: immunogene therapy, interleukin-15, carcinoembryonic antigen promoter, targeted gene expression effects. Many cytokines have been investigated in preclinical settings and phase I/II gene therapy clinical trials, including granulocyte-macrophage colony-stimulating factor, tumor necrosis factor- $\alpha$, IFN- $\gamma$ and the interleukins (2). Cytokinebased gene therapy was demonstrated to eliminate solid tumors in preclinical models, but only weak results were achieved in clinical trials with the currently available vectors. Low efficiency of transgene expression was associated with non-viral vectors, and safety concerns regarding the clinical implementation of viral vectors hampered the whole gene therapy field. However, advances in gene delivery and improvements in vector design are generating new momentum for gene therapy-based cancer treatment.

Interleukin-15 (IL-15) is a cytokine which acts on both innate and adaptive immune cells and promotes the survival, proliferation, activation and maintenance of natural killer and $\mathrm{CD}^{+} \mathrm{T}$ cells, as well as stimulating the function of neutrophils, macrophages and dendritic cells $(3,4)$. In this study, we aimed to construct an efficient IL-15 expression vector and target IL-15 expression to carcinoembryonic antigen (CEA)-positive tumor cells. Amplified IL-15 expression plasmid vector pHi2spIL15-CMV-tat and CEA-positive tumor-specific amplified IL-15 expression plasmid vector pHi2-spIL15-CEA-tat were constructed. In these vectors, the HIV2 promoter directed IL-15 expression, while its efficacy was enhanced by the CMV or CEA promoter driving transcription transactivator tat expression. Our data show that a significant amount of IL-15 was expressed, and that the CEA-specific positively-controlled IL-15 expression plasmid increased IL-15 efficiency in CEApositive human colon carcinoma SW480 cells. This research lays a foundation for further study to develop IL-15-based immunogene therapies for cancer in vivo.

\section{Materials and methods}

Cell lines. Human colon carcinoma SW480 cells and human breast carcinoma MCF-7 cells were obtained from American Type Culture Collection (Manassas, VA). All cells were maintained in RPMI-1640 medium supplemented with 10\% fetal bovine serum (Invitrogen, Beijing, P.R. China), $2 \mathrm{mM}$ glutamine, $1 \mathrm{mM}$ pyruvate, $50 \mu \mathrm{M} 2$-mercaptoethanol, penicillin $(200$ units $/ \mathrm{ml})$ and streptomycin $(200 \mu \mathrm{g} / \mathrm{ml})$ at $37^{\circ} \mathrm{C}$ in a $5 \% \mathrm{CO}_{2} / 95 \%$ air atmosphere. For gene-modified cells, Geneticin $(600 \mu \mathrm{g} / \mathrm{ml})$ (Invitrogen) was added to the medium. 


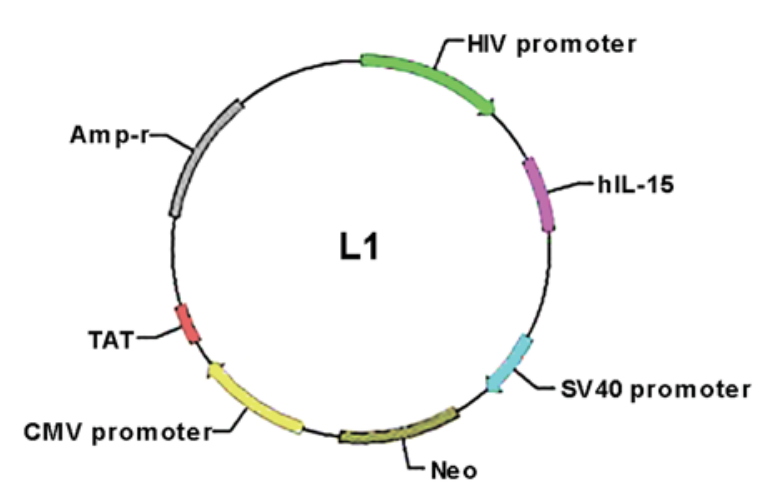

A

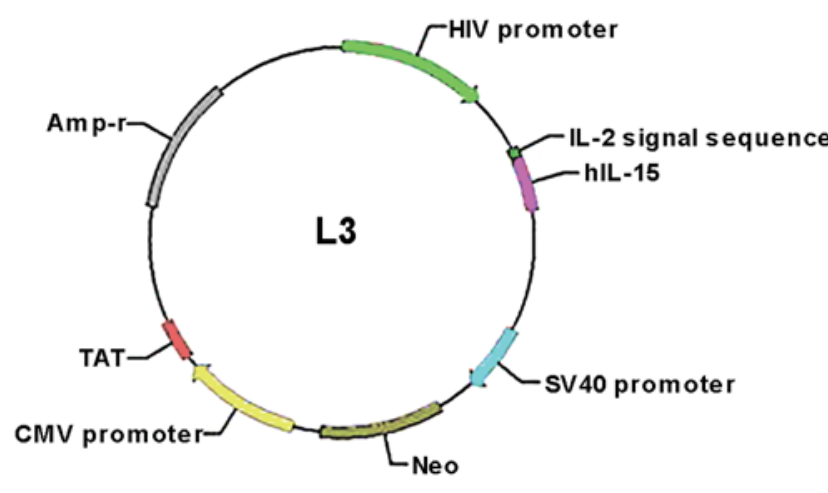

C

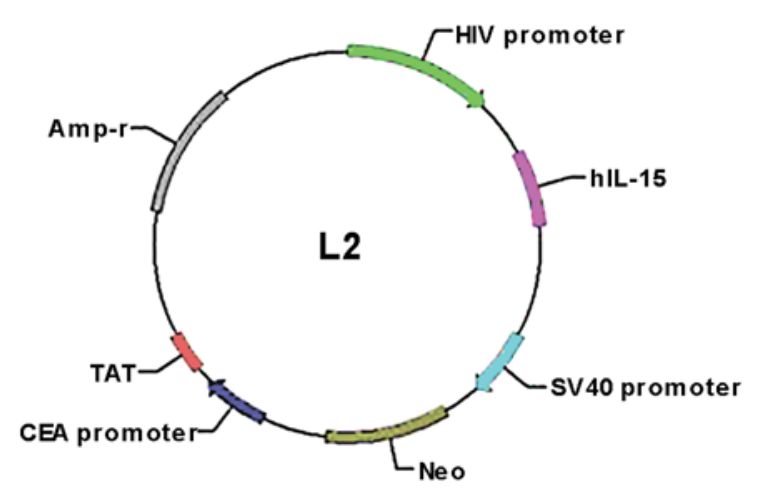

B

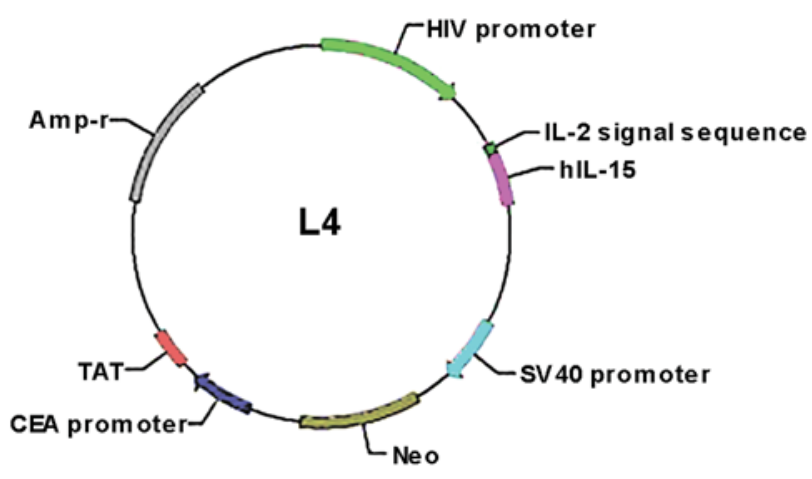

D

Figure 1. IL-15 expression genetic constructs. (A) pHi2-IL15-CMV-tat: the HIV2 promoter drives human IL-15 gene expression and the CMV promoter drives HIV transcriptional transactivator tat gene expression. (B) pHi2-IL15-CEA-tat: the HIV2 promoter drives human IL-15 gene expression and the CEA promoter drives tat gene expression. (C) pHi2-spIL15-CMV-tat: the HIV2 promoter drives human IL-15 gene expression, the signal sequence of IL-15 is replaced by the human IL-2 signal sequence, and the CMV promoter drives tat gene expression. (D) pHi2-spIL15-CMV-tat: the HIV2 promoter drives human IL-15 gene expression, the IL-15 signal sequence is replaced by the human IL-2 signal sequence, and the CEA promoter drives tat gene expression.

Genetic constructs. All restriction enzymes and their buffers were purchased from New England Biolabs (Beijing, P.R. China). The following plasmids were constructed.

pHi2-IL15-CMV-tat (L1). pHi2-IL15-CMV-tat was constructed by inserting the IL-15 gene fragment into the EcoRI and MulI sites behind the HIV2 promoter of the backbone plasmid pHi2-MCS-CMV-tat (M7) (kindly provided by Dr Harris, University of Arizona). Briefly, the IL-15 gene fragment was amplified from pORF-IL15 (Invivogen, San Diego, CA) using the following primers: upstream primer containing the EcoRI restriction site, 5'-CCGGCCGAATTCCGAAGGAGGGCC ACCATG-3'; and downstream primer containing the $M u l$ site, 5'-CCGGCCACGCGTTCAATTGCAATCAAGAAGT-3'. The PCR product was 538 bp. After digestion with EcoRI and $M u l I$, the IL-15 fragment was ligated into the same restriction sites in the plasmid pHi2-MCS-CMV-tat, resulting in the plasmid pHi2-IL15-CMV-tat (Fig. 1A).

pHi2-IL15-CEA-tat (L2). pHi2-IL15-CEA-tat was constructed by replacing the CMV promoter in pHi2-IL15-CMV-tat with the CEA promoter. Briefly, CEA promoter was amplified from pDRIVE-hCEA (Invivogen) using the following primers: upstream primer containing the SpeI site, 5'-GGCCGGACT AGTGCCCTGGAGAGC-3'; and downstream primer containing the SacI site, 5'-CCGGCCGAGCTCGGTCTCTGC
TGTCTGCTC-3'. The PCR product was 452 bp. After digestion with SpeI and SacI, the CEA promoter sequence was inserted into the same restriction sites of the plasmid pHi2MCS-CMV-tat, resulting in pHi2-MCS-CEA-tat. Then, the IL-15 gene fragment was inserted into the EcoRI and MulI sites as described above, resulting in the plasmid pHi2-IL15CEA-tat (Fig. 1B).

pHi2-spIL15-CMV-tat (L3). pHi2-spIL15-CMV-tat was constructed by replacing the IL-15 signal sequence with the IL-2 signal sequence by site-directed mutagenesis (Fig. 1C). Briefly, upstream and downstream primers were synthesized whose 5 ' ends were nucleotides corresponding exactly to the sequences upstream and downstream of the IL-15 signal sequence in the plasmid pHi2-IL15-CMV-tat. Their 3' ends were nucleotides corresponding exactly to the $5^{\prime}$ and $3^{\prime}$ end sequence of the IL-2 signal sequence in the plasmid pHi2IL2-CMV-tat (kindly provided by Dr Harris, University of Arizona). After PCR amplification using the pHi2-IL2CMV-tat as a template, the PCR product was harvested. According to the protocol described by the QuikChange ${ }^{\circledR}$ Site-Directed Mutagenesis Kit (Stratagene, La Jolla, CA), $1 \mu 1$ dNTP and $2.5 \mu 1$ PfuTurbo DNA polymerase were added to $250 \mathrm{ng}$ of the PCR product and $50 \mathrm{ng}$ of the plasmid pHi2IL15-CMV-tat for a final volume of $50 \mu \mathrm{l}$. The PCR reaction was denatured at $95^{\circ} \mathrm{C}$ for $30 \mathrm{sec}$, followed by 18 cycles for 
$30 \mathrm{sec}$ at $95^{\circ} \mathrm{C}, 1 \mathrm{~min}$ at $55^{\circ} \mathrm{C}$ and $8 \mathrm{~min}$ at $68^{\circ} \mathrm{C}$. At the end of the mutagenesis reaction, $10 \mathrm{U} D p n \mathrm{I}$ was added to the reaction tube and incubated at $37^{\circ} \mathrm{C}$ for $1 \mathrm{~h}$ to remove wildtype original methylated template DNA. The PCR product was then used to transform XL1-Blue Supercompetent cells. Clones were tested to verify the replacement by DNA sequence analysis (performed by Takara, Dalian, P.R. China).

pHi2-spIL15-CEA-tat (L4). To construct pHi2-spIL15-CEA-tat (Fig. 1D), the plasmid pHi2-spIL15-CMV-tat was digested with $E c o$ RI and $M u l I$ and the resulting fragment was inserted into the same sites in the plasmid pHi2-MCS-CEA-tat.

pHi2-EGFP-CEA-tat (L5) and pHi2-EGFP-CMV-tat (L6). In order to evaluate transfection efficiency, a gene-encoding enhanced green fluorescence protein (EGFP) was cloned into the same backbone plasmid behind the HIV2 promoter, resulting in the EGFP-expressing plasmids pHi2-EGFPCEA-tat and pHi2-EGFP-CMV-tat.

Cell transfection. Tumor cells were transfected with plasmid DNA using the cationic lipid Lipofectamine 2000 (Invitrogen) according to the manufacturer's protocol. Briefly, $24 \mathrm{~h}$ before transfection, cells were plated at a concentration of $5 \times 10^{5}$ cells/ well in $2 \mathrm{ml}$ of medium on 6-well plates and grown to 70-80\% confluency. DNA/lipid complexes were prepared $30 \mathrm{~min}$ before transfection. Plasmid DNA $(1 \mu \mathrm{g})$ and $3 \mu 1$ DMRIE-C were individually diluted in $250 \mu 1$ of OptiMEM medium (Gibco, Rockville, MD), mixed together, incubated at room temperature for $20 \mathrm{~min}$, then added to the well. Cells were incubated with lipid/DNA complexes for $4 \mathrm{~h}$. The medium was then replaced with fresh culture medium. Transfection efficiency was determined by simultaneous transfection of an EGFP expression plasmid. IL-15 expression was tested by ELISA.

ELISA for IL-15 production. At 24 and $48 \mathrm{~h}$ after transfection, the culture supernatants were collected and tested for IL-15 expression using an enzyme-linked immunosorbent assay (ELISA) according to the manufacturer's protocol (R\&D Systems, USA). Briefly, a 96-well plate was coated with antimouse IL-5 antibody and blocked with bovine serum albumincontaining buffer. After washing, a standardized IL-15 solution and the cell culture supernatants were added to the wells. Following $2 \mathrm{~h}$ of incubation, the plate was washed, then biotinlabeled detection antibody and avidin-horseradish peroxidase were added. After another 1-h incubation and washing, the substrate solution was added and the plate was read at $450 \mathrm{~nm}$.

Statistical analysis. Values were represented as the means \pm standard deviation (SD). Results were compared using the Student's t-test. p-values $<0.05$ were considered to be statistically significant.

\section{Results}

pHi2-IL15-CMV-tat gave rise to a significant amount of IL-15 expression in human tumor cells. The bioactivity of cytokines is related to their expression levels. In order to achieve a high level of IL-15 expression, we cloned the IL-15 gene into the

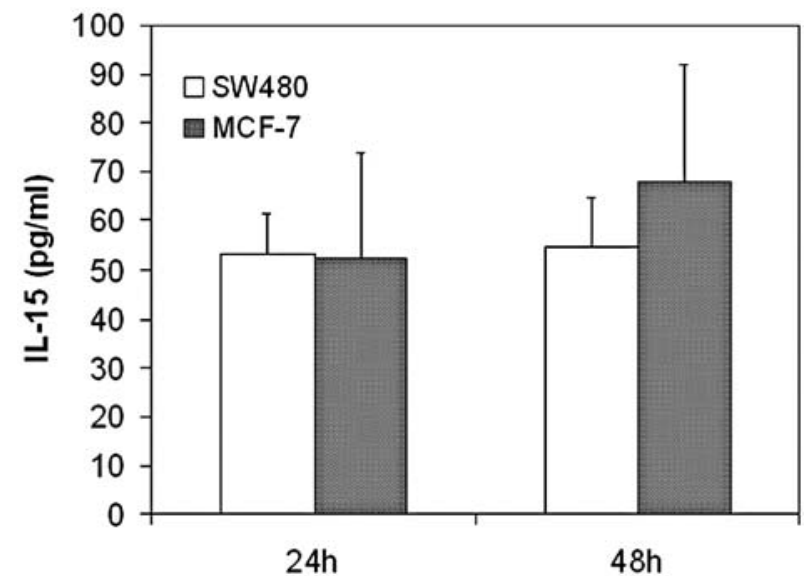

Figure 2. IL-15 expression by pHi2-IL15-CMV-tat-transfected cells. SW480 and MCF-7 cells were plated at a concentration of $5 \times 10^{5}$ cells/well in $2 \mathrm{ml}$ of medium on 6-well plates. After $24 \mathrm{~h}$, cells were transfected with IL-15 expression plasmid pHi2-IL15-CMV-tat using Lipofectamine 2000. Culture supernatants were collected at 24 and $48 \mathrm{~h}$ after transfection, and IL-15 expression was detected by ELISA. The mean \pm SD of three triplicate experiments are shown.

amplified gene expression vector pHi2-MCS-CMV-tat, which resulted in the plasmid pHi2-IL15-CMV-tat. In pHi2-IL15CMV-tat, the HIV2 promoter drives human IL-15 gene expression and CMV promoter HIV transcriptional activator tat gene expression. The expression of Tat protein enhances the transcription initiated by the HIV promoter. After transfection into human tumor MCF-7 and SW480 cells, a significant amount of IL-15 expression was achieved (Fig. 2). The transfection efficiency was $\sim 21 \%$ for both cell lines, determined by transfected EGFP-expressing plasmid pHi2-EGFP-CMVtat under the same conditions (data not shown).

Replacement of the IL-15 with the IL-2 signal sequence significantly enhanced IL-15 secretion of transfected cells. In order to further increase IL-15 expression, we replaced the IL-15 signal sequence with the human IL-2 signal sequence. In the plasmid pHi2-spIL15-CMV-tat, the IL-15 signal sequence was replaced by the IL-2 signal sequence using site-directed mutagenesis. Compared to pHi2-IL15-CMV-tat, pHi2-spIL15CMV-tat increased IL-15 expression 4.3-/5.9-fold and 5.4-/ 4.8 -fold (24/48 h) after being transfected into SW480 and MCF-7 cells, respectively (Fig. 3). These results indicate that the IL-2 signal peptide can more efficiently direct IL-15 secretion.

pHi2-spIL15-CEA-tat targeted IL-15 expression in CEApositive tumor cells. To target IL-15 expression to tumor tissue we constructed the plasmid pHi2-spIL15-CEA-tat, the tumorspecific CEA promoter of which controls tat expression. HIV2 promoter is weak without Tat. Through this modification, IL15 expression was low in CEA-negative tumors, but high in CEA-positive tumors. After transfection, the plasmid pHi2spIL15-CEA-tat produced 7.0- and 9.8-fold increases in the level of IL-15 at 24 and $48 \mathrm{~h}$, respectively, after transfection into SW480 cells compared with transfection into MCF-7 cells (Fig. 4). These results indicate that the CEA promoter can efficiently drive tat expression and amplify IL-15 expression in turn. 

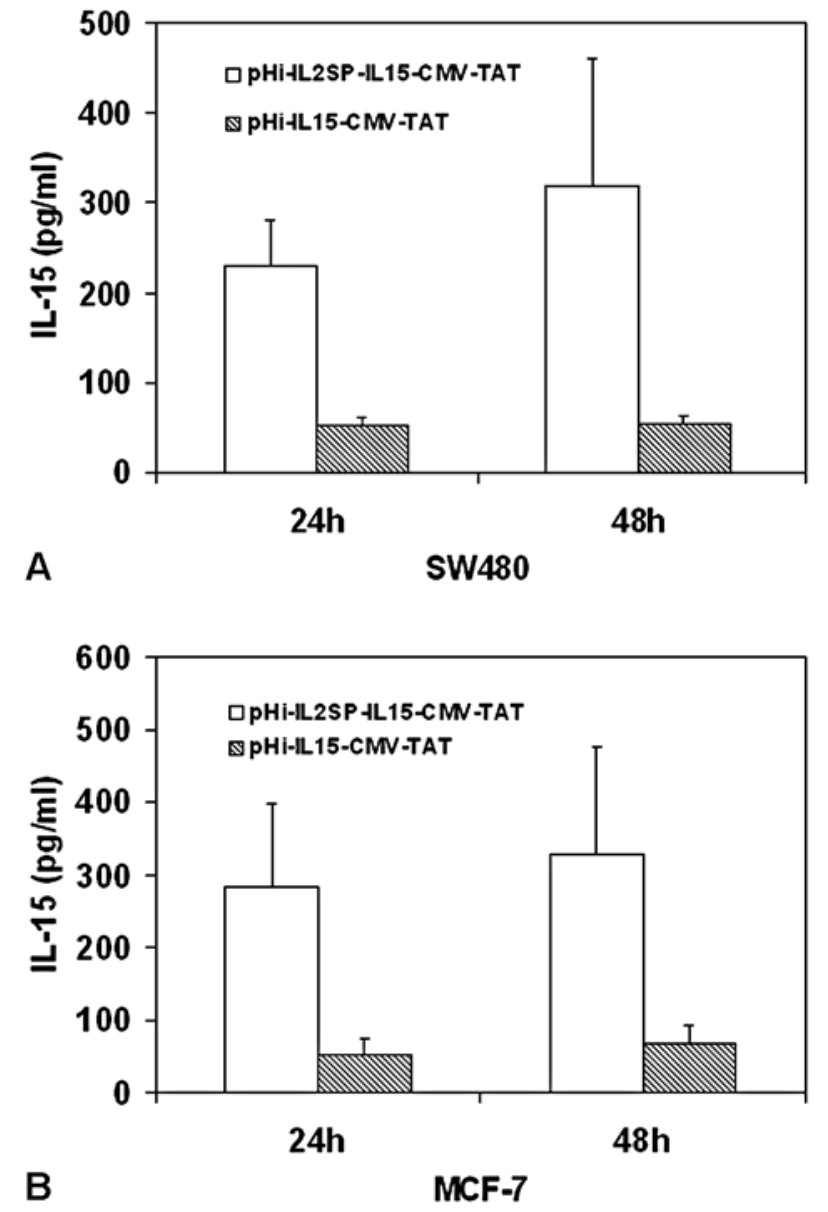

Figure 3. Increased IL-15 expression by the replacement of the IL-15 with IL-2 signal sequence. SW480 (A) and MCF-7 (B) cells were plated at a concentration of $5 \times 10^{5}$ cells $/$ well in $2 \mathrm{ml}$ of medium on 6 -well plates. After $24 \mathrm{~h}$, cells were separately transfected with the plasmids pHi2-spIL15-CMVtat and pHi2-IL15-CMV-tat using Lipofectamine 2000. Culture supernatants were collected at 24 and $48 \mathrm{~h}$ after transfection, and IL-15 expression was detected by ELISA. The mean \pm SD of three triplicate experiments are shown.

Comparable levels of IL-15 expression were achieved by CEA-specific IL-15 expression plasmid in CEA-positive cells. To compare the IL-15 expression of pHi2-spIL15-CEA-tat with that of pHi2-spIL15-CMV-tat in CEA-positive tumor cells, we transfected both plasmids into SW480 cells. The supernatants of transfected cells were harvested at 24 and $48 \mathrm{~h}$ after transfection, and the results indicate that comparable levels of IL-15 were expressed by both plasmids in SW480 cells. At $24 \mathrm{~h}$ after transfection, expression by pHi2-spIL15CEA-tat was $332.49 \pm 151.32 \mathrm{pg} / \mathrm{ml}$, whereas that of $\mathrm{pHi} 2$ spIL15-CMV-tat was $229.69 \pm 52.37 \mathrm{pg} / \mathrm{ml}(\mathrm{p}=0.361)$. At $48 \mathrm{~h}$, expression by pHi2-spIL15-CEA-tat was $341.12 \pm 44.78 \mathrm{pg} / \mathrm{ml}$, whereas that of pHi2-spIL15-CMV-tat was $320.73 \pm 139.00 \mathrm{pg}$ / $\mathrm{ml}(\mathrm{p}=0.998)$ (Fig. 5).

\section{Discussion}

With the dissection of the molecular mechanism of carcinogenesis and tumor progression, great progress in gene therapy for cancer has been made. In fact, over two-thirds of gene therapy clinical trials currently target cancer. Of the approaches to cancer gene therapy, immunotherapy predominates. Gene transfer is being used to overcome the low immunogenicity

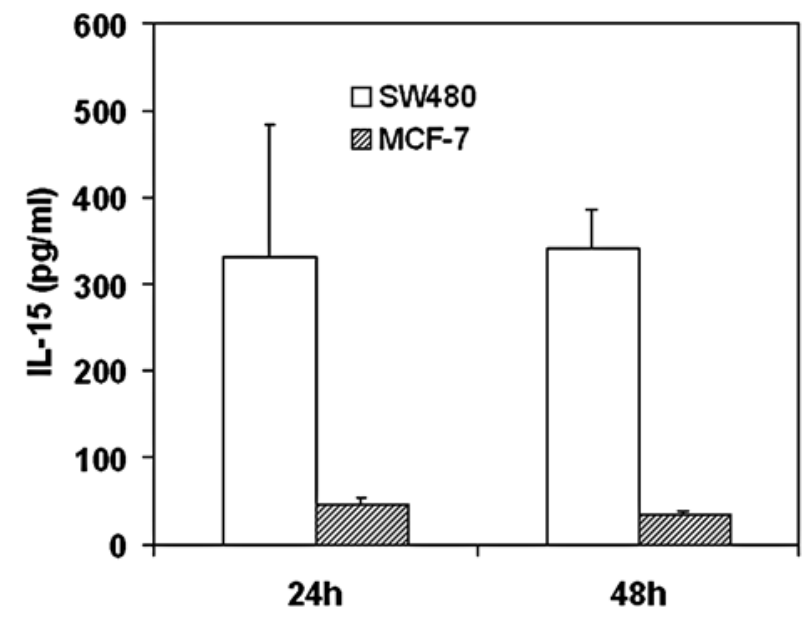

Figure 4. CEA-specific IL-15 expression by pHi2-spIL15-CEA-tat. SW480 and MCF-7 cells were plated at a concentration of $5 \times 10^{5}$ cells/well in $2 \mathrm{ml}$ of medium on 6-well plates. After $24 \mathrm{~h}$, cells were transfected with pHi2-spIL15CEA-tat using Lipofectamine 2000. Culture supernatants were collected at 24 and $48 \mathrm{~h}$ after transfection, and IL-15 expression was detected by ELISA. The mean \pm SD of three triplicate experiments are shown.

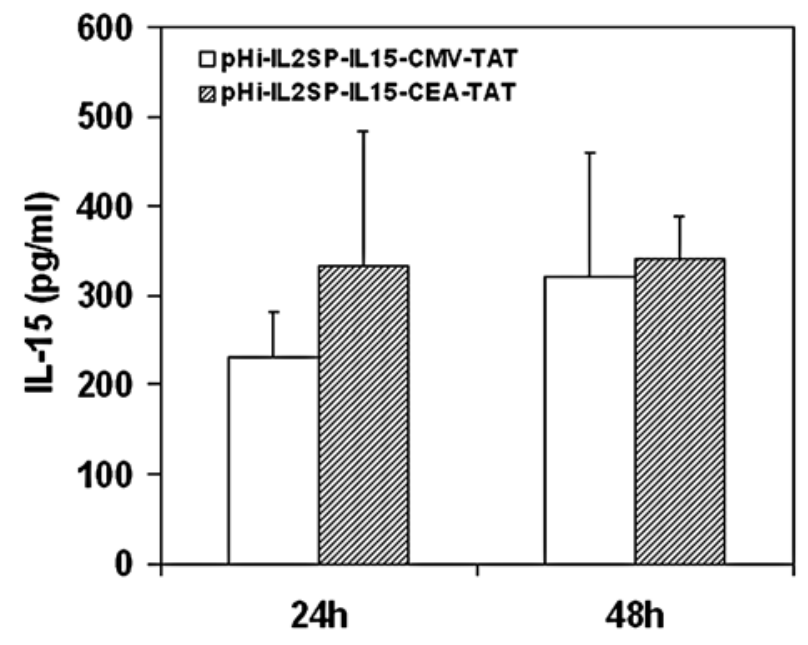

Figure 5. IL-15 expression of SW480 cells transfected with pHi2-spIL-15CEA-tat and pHi2-spIL-15-CMV-tat. SW480 cells were plated at a concentration of $5 \times 10^{5}$ cells/well in $2 \mathrm{ml}$ of medium on 6 -well plates. After $24 \mathrm{~h}$, cells were separately transfected with pHi2-spIL-15-CEA-tat and pHi2-spIL15-CMV-tat using Lipofectamine 2000. Culture supernatants were collected at 24 and $48 \mathrm{~h}$ after transfection, and IL-15 expression was detected by ELISA. The mean \pm SD of three triplicate experiments are shown.

and immune evasion of malignant cells. Cytokines are a group of proteins or peptides which play an important role in the regulation of immune responses. Recombinant cytokines, such as IL-2 and IFN- $\gamma$, have been used in clinical settings. However, their application is impeded by their systemic toxicity in high therapeutic doses (5). The transfer of genes encoding immunostimulatory cytokines in vivo and ex vivo to tumor cells consequently becomes an attractive approach. Cytokines locally expressed by tumor cells can augment tumor antigen presentation, as well as recruit tumor-specific immune cells. Many cytokines have been investigated in preclinical studies, including granulocyte-macrophage colony-stimulating factor, tumor necrosis factor- $\alpha$, IFN- $\gamma$ and the interleukins $(6,7)$. 
IL-15 is a pleiotropic cytokine that plays a key role in the regulation of both innate and adaptive immune responses. First isolated from a simian kidney epithelial cell line in 1994 by Grabstein et al (8), it promotes the survival, proliferation, activation and maintenance of natural killer and $\mathrm{CD} 8^{+} \mathrm{T}$ cells, as well as stimulating the function of neutrophils, macrophages and dendritic cells. Increased anti-tumor activity was reported following IL-15 administration to tumor-bearing mice in 1995 (9). However, although the cyokine has been known in the field of cancer gene therapy since shortly after its discovery (10), few preclinical studies have analyzed the effects of IL-15 gene transfer. Yajima et al demonstrated that overexpression of IL-15 in vivo enhanced anti-tumor activity against malignant melanoma through augmented NK activity and cytotoxic T-cell response (11). Araki et al reported that weakly immunogenic murine colon 26 cells could be completely rejected when expressing a high level of IL-15 (12). Vera et al showed that dendritic cells transferred with IL-15 have an enhanced capability to induce curative anti-tumor immunity when injected into malignant lesions (13). In this study, we constructed amplified IL-15 expression plasmid vector pHi2-spIL15CMV-tat and CEA-specific amplified IL-15 expression vector plasmid pHi2-spIL15-CEA-tat to achieve a high level of IL-15 expression for cancer gene therapy.

Efficient expression of the therapeutic gene in target tissue is the prerequisite for gene therapy. Cytokine genes can be delivered through the use of viral or non-viral vectors. The main problems encountered when using viral vector systems are toxicity and immunogenicity, as well as a possible insertion mutation for retroviral vectors. Plasmid-based nonviral vectors hold great promise for future gene therapy due to their safety, stability, low cost and, most importantly, the progress of physical methods in gene transfer (14-16). High levels of transgene expression have been achieved by modified plasmid vectors. Tsang et al constructed an amplified plasmid vector, pHi2-IL2-CMV-tat, which gave rise to a 28-fold increase in IL-2 expression compared to the CMV promoterdriven IL-2 expression plasmid (17). In this study, based on a sample backbone, we constructed the IL-15 expression plasmid pHi2-IL15-CMV-tat, among others. In these plasmids, the CMV promoter controlled HIV tat and, upon expression, the Tat protein mediated the transcriptional transactivation of HIV2 LTR, which directed IL-15 expression. Bamford et al reported that replacing the IL-15 with the IL-2 signal peptide increased IL-15 expression up to 20-fold (18). Therefore, in order to further increase the IL-15 expression of our vector, we successfully replaced the IL-15 with the IL-2 signal sequence by site-directed mutagenesis. Our data show a 5.9-fold increase in IL-15 expression after replacement. Consequently, by cloning the IL-15 gene into the amplified vector and replacing the IL-15 signal sequence with the IL-2 signal sequence, efficient IL-15 expression was achieved.

Targeting therapeutic genes to tumor cells could improve the effect of gene therapy and could lower systemic side effects. Strategies using tumor-specific promoters in conjunction with therapeutic genes have been attempted. CEA is a membrane oncofetal glycoprotein expressed on most adenocarcinomas of the gastrointestinal tract and on lung and breast cancer (19). Utilization of the CEA promoter to target therapeutic genes to CEA-positive tumors has been investigated
$(20,21)$. However, the low efficiency of the CEA promoter limits its application. In the present study, we constructed the IL-15 expression plasmid vector pHi2-spIL15-CEA-tat. In this plasmid, the CEA promoter was used to direct HIV tat expression, while HIV2 LTR drove IL-15 expression. Expression of Tat controlled by the CEA promoter transactivated HIV2 LTR, achieving a high level of IL-15 expression in CEA-positive tumor cells. Our data show that pHi2-spIL15CEA-tat gave rise to a very basic level of IL-15 expression in CEA-negative cells because the HIV2 promoter was inefficient in directing transgene expression without Tat, whereas it increased IL-15 expression 10-fold in CEA-positive cells. In addition, the expression level of IL-15 was comparable to CMV promoter-directed tat expression plasmid pHi2-spIL15CMV-tat in CEA-positive cells. The underlying mechanism could be that the cumulative activity of Tat on the HIV promoter renders the need for a strong promoter to drive expression unecessary. The pHi2-spIL15-CEA-tat expression vector may provide a feasible strategy for the locallyinducible, and hence safer, high-level expression of IL-15 for anti-cancer gene therapy.

We constructed an amplified IL-15 expression plasmid vector, pHi2-spIL15-CMV-tat, and a CEA promotercontrolled amplified IL-15 expression plasmid vector, pHi2spIL15-CEA-tat. A high level of IL-15 and targeted expression were achieved after transfection into tumor cells. Our results confirm that incorporating amplifier strategy into a single vector expression cassette significantly enhances transgene expression. Furthermore, an inefficient low activity tumorspecific promoter can be used in the amplified vector to achieve targeted high-level gene expression.

\section{Acknowledgements}

This project was sponsored by the Scientific Research Foundation for the Returned Overseas Chinese Scholars, State Education Ministry (to X.H.) and the Research Foundation of Tianjin Medical University (to X.H.).

\section{References}

1. http://www.wiley.co.uk/genmed/clinical/, 2007.

2. Podhajcer OL, Lopez MV and Mazzolini G: Cytokine gene transfer for cancer therapy. Cytokine Growth Factor Rev 18: 183-194, 2007.

3. Tagaya Y, Bamford RN, De Filippis AP and Waldmann TA: IL-15: a pleiotropic cytokine with diverse receptor/signaling pathways whose expression is controlled at multiple levels. Immunity 4 : 329-336, 1996.

4. Carson WE, Fehniger TA, Haldar S, Eckhert K, Lindemann MJ, Lai CF, Croce CM, Baumann $\mathrm{H}$ and Caligiuri MA: A potential role for interleukin-15 in the regulation of human natural killer cell survival. J Clin Invest 99: 937-943, 1997.

5. Dranoff G: Cytokines in cancer pathogenesis and cancer therapy. Nat Rev Cancer 4: 11-22, 2004.

6. Hogge GS, Burkholder JK, Culp J, Albertini MR, Dubielzig RR, Yang NS and MacEwen EG: Preclinical development of human granulocyte-macrophage colony-stimulating factor-transfected melanoma cell vaccine using established canine cell lines and normal dogs. Cancer Gene Ther 6: 26-36, 1999.

7. Zang Z, Mahendran R, Wu Q, Yong T and Esuvaranathan K: Nonviral tumor necrosis factor-alpha gene transfer decreases the incidence of orthotopic bladder tumors. Int J Mol Med 14: 713-717, 2004.

8. Grabstein KH, Eisenman J, Shanebeck K, Rauch C, Srinivasan S, Fung V, Beers C, Richardson J, Schoenborn MA and Ahdieh M: Cloning of a $\mathrm{T}$ cell growth factor that interacts with the beta chain of the interleukin-2 receptor. Science 264: 965-968, 1994. 
9. Munger W, De Joy SQ, Jeyaseelan R Sr, Torley LW, Grabstein KH, Eisenmann J, Paxton R, Cox T, Wick MM and Kerwar SS: Studies evaluating the antitumor activity and toxicity of inter-leukin-15, a new $\mathrm{T}$ cell growth factor: comparison with interleukin-2. Cell Immunol 165: 289-293, 1995.

10. Ferrini S, Azzarone B and Jasmin C: Is IL-15 a suitable candidate for cancer gene therapy? Gene Ther 8: 656-657, 1996.

11. Yajima T, Nishimura H, Wajjwalku W, Harada M, Kuwano $H$ and Yoshikai Y: Overexpression of interleukin-15 in vivo enhances antitumor activity against MHC class I-negative and -positive malignant melanoma through augmented NK activity and cytotoxic T-cell response. Int J Cancer 99: 573-578, 2002.

12. Araki A, Hazama S, Yoshimura K, Yoshino S, Iizuka N and Oka M: Tumor secreting high levels of IL-15 induces specific immunity to low immunogenic colon adenocarcinoma via $\mathrm{CD}^{+}$ T cells. Int J Mol Med 14: 571-576, 2004.

13. Vera M, Razquin N, Prieto J, Melero I, Fortes P and GonzalezAseguinolaza G: Intratumoral injection of dendritic cells transduced by an SV40-based vector expressing interleukin-15 induces curative immunity mediated by $\mathrm{CD} 8^{+} \mathrm{T}$ lymphocytes and NK cells. Mol Ther 12: 950-959, 2005.

14. Heller R, Schultz J, Lucas ML, Jaroszeski MJ, Heller LC, Gilbert RA, Moelling K and Nicolau C: Intradermal delivery of interleukin-12 plasmid DNA by in vivo electroporation. DNA Cell Biol 20: 21-26, 2001.

15. Wells DJ: Gene therapy progress and prospects: electroporation and other physical methods. Gene Ther 11: 1363-1369, 2004.
16. Martiniuk F, Chen A, Mack A, Donnabella V, Slonim A, Bulone L, Arvanitopoulos E, Raben N, Plotz P and Rom WN: Helios gene gun particle delivery for therapy of acid maltase deficiency. DNA Cell Biol 21: 717-725, 2002.

17. Tsang TC, Brailey JL, Vasanwala FH, Wu RS, Liu F, Clark PR, Meade-Tollin L, Luznick L, Stopeck AT, Akporiaye ET and Harris DT: Construction of new amplifier expression vectors for high levels of IL-2 gene expression. Int J Mol Med 5: 295-300, 2000 .

18. Bamford RN, De Filippis AP, Azimi N, Kurys G and Waldmann TA: The 5' untranslated region, signal peptide, and the coding sequence of the carboxyl terminus of IL-15 participate in its multifaceted translational control. J Immunol 160: 4418-4426, 1998.

19. Shively JE and Beatty JD: CEA-related antigens: molecular biology and clinical significance. Crit Rev Oncol Hematol 2: 355-399, 1985.

20. Richards CA, Austin EA and Huber BE: Transcriptional regulatory sequences of carcinoembryonic antigen: identification and use with cytosine deaminase for tumor-specific gene therapy. Hum Gene Ther 6: 881-893, 1995.

21. Lan KH, Kanai F, Shiratori Y, Okabe S, Yoshida Y, Wakimoto H, Hamada H, Tanaka T, Ohashi M and Omata M: Tumor-specific gene expression in carcinoembryonic antigen-producing gastric cancer cells using adenovirus vectors. Gastroenterology 111: 1241-1251, 1996. 